\title{
Randomized multicenter noninferiority phase III clinical trial of the first biosimilar of eculizumab
}

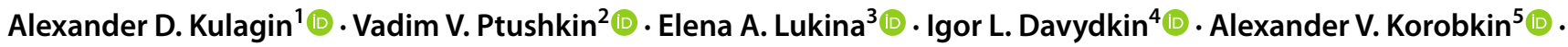 \\ Vladimir S. Shamrai ${ }^{6}$ ( Tatyana S. Konstantinova ${ }^{7}$ (1) $\cdot$ Tatyana S. Kaporskaya $^{8}$ (D) - Tatyana A. Mitina9 ${ }^{9}$.

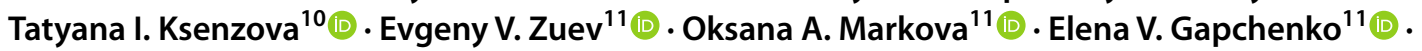 \\ Dmitry A. Kudlay ${ }^{11,12}$
}

Received: 8 January 2021 / Accepted: 24 July 2021 / Published online: 16 August 2021

(c) The Author(s) 2021

\begin{abstract}
Currently, eculizumab is the main effective treatment for paroxysmal nocturnal hemoglobinuria (PNH). The aim of this randomized multicenter noninferiority study was to evaluate the efficacy and safety of the Biosimilar (Elizaria) in comparison with the Originator (Soliris) in patients with PNH. Biosimilar and Originator were administered at a dose of $600 \mathrm{mg}$ weekly for 4 weeks at the initial stage in naive patients, as well as for maintenance therapy at a dose of $900 \mathrm{mg}$ every 2 weeks in all patients. The primary endpoint was a comparative assessment of hemolytic activity based on the area under the lactate dehydrogenase (LDH) concentration-time curve during the maintenance therapy. Thirty-two (32) patients were randomized for therapy with Biosimilar $(n=16)$ or Originator $(n=16)$. The mean values of LDH concentration-time curve were similar in both treatment groups without statistically significant differences $(p>0.05)$. Evaluation of secondary endpoints has shown no statistically significant differences between the groups. Safety values were comparable in both treatment groups. The data obtained confirm that the Biosimilar is not inferior to the Originator in terms of the main efficacy parameter, and is also comparable with it in terms of safety and additional efficacy parameters. Clinicaltrials.gov identifier: NCT04463056
\end{abstract}

Keywords Paroxysmal nocturnal hemoglobinuria $\cdot$ Eculizumab $\cdot$ Biosimilar $\cdot$ Efficacy $\cdot$ Safety

\section{Introduction}

Paroxysmal nocturnal hemoglobinuria (PNH) is a rare clonal hematological disease that develops as a result of the clonal expansion in one or more clones of hematopoietic stem cells due to the somatic mutation of the $P I G$ - $A$ gene localized on the active $X$ chromosome [1]. This genetic defect results in the disturbance of early synthesis of the carbohydrate branch

Alexander D. Kulagin

kulagingem@rambler.ru

1 RM Gorbacheva Research Institute, Pavlov University, 6/8 L'va Tolstogo St, Saint Petersburg 197022, Russia

2 Botkin Moscow City Clinical Hospital, Moscow, Russia

3 National Medical Research Center for Hematology, Moscow, Russia

4 Samara State Medical University, Samara, Russia

5 Chelyabinsk Regional Clinical Hospital, Chelyabinsk, Russia

6 Rostov Regional Clinical Hospital, Rostov-on-Don, Russia of glycosylphosphatidylinositol (GPI) anchor involved in the fixation of a number of molecules that protect blood cell membranes against the damaging effect of the complement system (CD55, CD59). Activation of the complement system leads to the $\mathrm{C} 5 \mathrm{~b}$ protein formation, which is a key subunit in the formation of a membrane attack complex (MAC) followed by blocking of the complement inhibitor CD59 [2-4]. MAC is a key factor causing intravascular hemolysis,

7 Sverdlovsk Regional Clinical Hospital No. 1, Yekaterinburg, Russia

8 Irkutsk Regional Clinical Hospital, Irkutsk, Russia

9 Moscow Regional Clinical Research Institute Named After M.F. Vladimirsky, Moscow, Russia

10 Tyumen Regional Clinical Hospital No. 1, Tyumen, Russia

11 JSC GENERIUM, Volginsky Settlement, Vladimir Region, Russia

12 I.M. Sechenov First Moscow State Medical University (Sechenov University), Moscow, Russia 
platelet activation, and formation of procoagulant membrane microparticles [5-9].

The current pathogenetic treatment for $\mathrm{PNH}$-associated intravascular hemolysis is eculizumab, a humanized monoclonal antibody against complement component $\mathrm{C} 5$. In most patients, eculizumab treatment reverses all intravascular hemolysis manifestations, prevents severe complications, and, eventually, normalizes survival and quality of life of PNH patients $[10,11]$.

Elizaria (eculizumab), developed by the Russian biotechnological company JSC GENERIUM, was registered in the Russian Federation in 2019 for pathogenetic therapy of patients with $\mathrm{PNH}$ and atypical hemolytic uremic syndrome as a Biosimilar to the original product Soliris (Alexion Pharma GmbH).

At all stages of the development and production of the Biosimilar, a comprehensive study of the quality, safety, and efficacy of the medicinal product was performed in accordance with the regulatory requirements of the Eurasian Union (EAEU) and the European Medicines Agency (EMA) [12-14]. During the development of the Biosimilar, in vitro and in vivo preclinical studies were performed in comparison with the Originator (Soliris, Alexion Pharma $\mathrm{GmbH}$, Switzerland). The results have shown the equivalence of medicinal products in terms of in vitro activity and toxicity. The phase I clinical study involving 30 healthy volunteers provided comparable safety and tolerability data for the Biosimilar and Originator. In the phase Ib study in 11 PNH patients, the pharmacokinetic and pharmacodynamic properties of the Biosimilar were studied, confirming its efficacy and demonstrating the safety [15].

The phase III ECU-PNH-III study (clinicaltrials.gov identifier: NCT04463056) was conducted to show that the investigational medicinal product is not inferior to the Originator in terms of area under the LDH concentration-time curve (LDH AUC) (noninferiority design). The results of the study were partially reported at the 2019 ASH Annual Meeting [16]. All clinical trial activities were funded by JSC GENERIUM.

\section{Methods}

\section{Patients}

The study was conducted at 10 accredited medical centers in Russia and included 32 patients from 23 to 71 years of age, with PNH confirmed by flow cytometry to assess the size of the PNH clone among red blood cells (RBC), granulocytes, and monocytes, with intravascular hemolysis and concomitant clinical symptoms at present or in past medical history with or without eculizumab administration. PNH clone testing was performed according to the previously described protocol of high-sensitivity flow cytometry [17]. All patients were vaccinated against meningococcal infection with a tetravalent vaccine (Neisseria meningitidis serotypes A, C, $\mathrm{Y}$, and W135). For naive patients, it was obligatory to exceed the LDH upper limit of normal by 1.5 times. The key exclusion criteria were the presence of diseases associated with bone marrow failure with the PNH clone (aplastic anemia, myelodysplastic syndrome, idiopathic myelofibrosis), previous infectious diseases caused by Neisseria meningitidis, active nonspecific infectious diseases, and completion of eculizumab treatment less than 70 days before the enrollment. Informed consent was obtained from all patients for being included in the study prior to any procedure.

\section{Study design}

A randomized, open-label, comparative, multicenter study was approved by the Ministry of Health of Russia (No. 546 dated October 17, 2017) and the Ethics Committee of $\mathrm{MoH}$ (No. 153 eff. date August 22, 2017) and was conducted in accordance with the ethical standards of the responsible committees on human experimentation (national and local) and with the Helsinki Declaration of 1975, as revised in 2013. The study consisted of the following periods: Screening up to 4 weeks, Treatment (26 weeks), and Follow-up (2 weeks).

\section{Treatment}

Patients were allocated by variable block size ( 4 and 6 block random allocation sequence was generated by biostatistician in Stata14) randomization using the IVRS system with a 1:1 ratio into two groups: Group $\mathrm{A}$, in which patients received the Biosimilar (Elizaria), and Group B, in which patients received the Originator (Soliris). Preliminary stratification was performed depending on the status of previous treatment with eculizumab (patients not receiving eculizumab/ patients receiving a maintenance dose of eculizumab before enrollment in the study). Eculizumab-naive patients in both groups received the initial cycle of therapy consisting of four weekly intravenous administrations of the medicinal product at a dose of $600 \mathrm{mg}$, with subsequent maintenance therapy at a dose of $900 \mathrm{mg}$ every 2 weeks. Patients previously treated with eculizumab started the treatment at the maintenance dose.

\section{Investigations}

Evaluation of the pharmacokinetic (PK) parameters of the medicinal product was performed based on the determination of total (free and bound) eculizumab by biolayer interferometry (Octet ${ }^{\circledR}$ QKe System (Pall ForteBio)) with using Octet ${ }^{\circledR}$ Software, v.10.0 (Pall ForteBio). The following 
basic pharmacokinetic (PK) parameters were calculated: minimum product concentration $\left(\mathrm{C}_{\min }\right)$, maximum product concentration $\left(\mathrm{C}_{\max }\right)$, minimum product concentration at the end of the dosing interval after establishing a stationary distribution $\left(\mathrm{C}_{\text {trough }}\right)$, area under the concentration-time curve throughout the dosing interval after establishing a stationary distribution $\left(\mathrm{AUC}_{\mathrm{t}, \mathrm{ss}}\right)$. As additional $\mathrm{PK}$ parameters, the time to reach the maximum product concentration $\left(\mathrm{T}_{\max }\right)$, elimination constant $\left(\mathrm{K}_{\mathrm{el}}\right)$, medicinal product elimination half-life $\left(\mathrm{T}_{1 / 2}\right)$, mean retention time of medicinal product in the systemic circulation (MRT), clearance $(\mathrm{Cl})$, and stationary volume of distribution $\left(\mathrm{V}_{\mathrm{ss}}\right)$ were calculated.

The analysis of pharmacodynamic (PD) parameters included evaluation of the membrane attack complex concentration in the blood serum (MAC, C5b-9) by the enzyme-linked immunosorbent assay (MicroVue Complement SC5b-9 Plus EIA MicroVue Complement SC5b-9 Plus EIA (Quidel, USA)) at the same time periods as for the PK assessment.

The safety of therapy was assessed by the incidence and severity of adverse drug reactions (ADRs) according to symptoms, physical examination, assessment of vital signs, electrocardiography (ECG), laboratory and instrumental studies, and patient diaries.

Immunogenicity was determined by the level of anti-drug antibodies, including the neutralizing activity of antibodies to eculizumab, by the method based on the bridging enzymelinked immunosorbent assay. The evaluation was performed at $1,5,13,21$ weeks of treatment and after the end of the treatment.

All data was collected using the platform EDC system CSOnline version 7.5.501.1 by Ennov clinical ${ }^{\circledR}$.

\section{Endpoints}

Comparative evaluation of hemolysis activity based on the area under the LDH concentration-time curve (LDH AUC) during the maintenance therapy with the investigational or reference product was the primary endpoint of the study. The secondary points included the area under the LDH concentration-time curve (LDH AUC) during 26 weeks of treatment, the number of packed red blood cells (pRBC) transfusions performed, the change in the values of the Functional Assessment of Chronic Illness Therapy-Fatigue Scale (FACIT-Fatigue) and the European Organization for Research and Treatment of Cancer Quality of Life Questionnaire (EORTC QLQ-C30), the number/proportion of patients with various thrombotic complications, patients requiring $\mathrm{pRBC}$ transfusions, and patients with breakthrough hemolysis.

\section{Statistical analysis}

The standard methods available in Stata (StataCorp LLC), version 14 , were used to analyze the data. The PK and PD data analysis was performed using the PkSolver software. LDH AUC during the period of maintenance therapy with the investigational or reference product was performed to assess the primary efficacy endpoint in terms of chronic hemolysis in a PP population. To demonstrate the difference in LDH AUC between the groups, a 95\% confidence interval was built, which should not have crossed the noninferiority boundary, which is set in this study as $50 \%$ of the previously identified placebo-controlled effect at a value of 150,635 U/L*days[18]. The $\chi 2$ criterion or Fisher's exact test was used to analyze the secondary efficacy parameters, which are categorical variables. Descriptive statistics was used to analyze the secondary efficacy parameters, which are quantitative variables. For the intergroup analysis, Student's $t$-test or Mann-Whitney test was used, depending on the type of data distribution. A normality test was performed using the Shapiro-Wilk test.

\section{Results}

\section{Patients}

Investigators screened 37 patients, 32 of whom (86.5\%) met all the inclusion/exclusion criteria and were randomized into two treatment groups. Twenty-two of the 32 randomized patients $(68.9 \%)$ had previously received treatment with Soliris, and 10 patients (31.3\%) had not received prior treatment with eculizumab. Two patients discontinued the study early and were excluded from the PP population due to the development of a serious adverse event "Myelodysplastic syndrome," and because of significant violations of the study protocol (Fig. 1). The median age of patients was 39 years in Group A and 36.5 years in Group B (Table 1). The study included 15 male patients and 17 female patients. For most of the baseline characteristics, the patients of both groups were comparable. There was a significantly higher LDH level in previously untreated patients and probably due to this reason a lower GFR in Group A.

\section{Pharmacokinetics}

Mean eculizumab steady-state concentration 5 min before the administration of the Biosimilar or Originator was $92.16 \pm 38.59 \mu \mathrm{g} / \mathrm{mL}$ in Group A and 133.21 \pm 71.56 in Group B. There were no statistically significant differences between the groups in eculizumab concentration $(p>0.05)$ at the majority of the time points. Both PK curves are in 
Fig. 1 Distribution of patients in the study

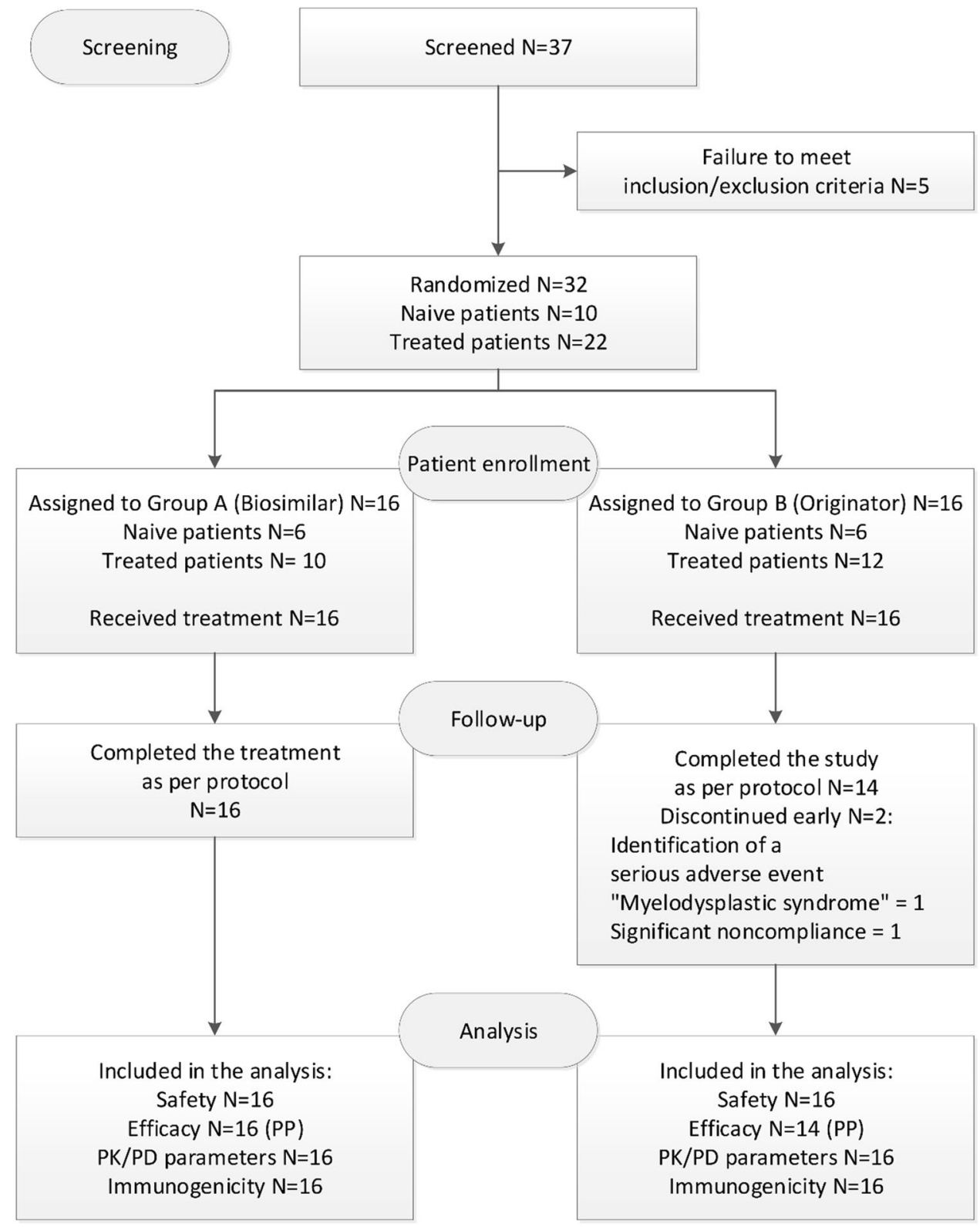

good agreement: the concentration of the medicinal product increases significantly after the end of the infusion, reaches a maximum at " $1 \mathrm{~h}$ after the end of infusion" point, and then gradually decreases (Fig. 2). Intergroup comparison of the PK parameters revealed no statistically significant differences $(p>0.05)$ (Table 2).

\section{Pharmacodynamics}

There were no statistically significant differences between the groups in MAC concentration $(p>0.05)$ at the majority of the time points. One $p$-value ranged from 0.01 to
0.05 (Visit 11 , point $1 \mathrm{~h}$ after the end of the infusion, $p=0.0237$ ), which, given the multiplicity of comparisons, also cannot be considered statistically significant differences. Both PD curves are in good agreement: MAC concentration decreases upon the medicinal product infusion completion, then it gradually increases, and reaches its maximum at the end of the dosing interval (Fig. 3).

\section{Efficacy}

Similar LDH AUC values were observed in both treatment groups, given the high coefficient of variation. Average 
Table 1 Baseline characteristics of the patients enrolled

\begin{tabular}{|c|c|c|c|}
\hline Variable & $\begin{array}{l}\text { Group A (Biosimi- } \\
\text { lar) }(N=16)\end{array}$ & $\begin{array}{l}\text { Group B (Origina- } \\
\text { tor })(N=16)\end{array}$ & $P$-value \\
\hline Age-years & & & 0.771 \\
\hline Median & 39 & 36.5 & \\
\hline$Q 1-Q 3$ & $30.5-58$ & $30-58$ & \\
\hline Female sex - no. (\%) & $7(43.8)$ & $10(62.5)$ & 0.288 \\
\hline White race - no. ${ }^{\dagger}$ & 16 & 16 & 1.000 \\
\hline History of thrombosis - no. (\%) & $2(12.5)$ & $4(25)$ & 0.327 \\
\hline History of aplastic anemia - no. (\%) & $5(31.3)$ & $1(6.3)$ & 0.086 \\
\hline \multicolumn{4}{|l|}{ Lactate Dehydrogenase } \\
\hline Naive Median - U/liter & 2,121 & 538 & 0.057 \\
\hline$Q 1-Q 3$ & $1,657-2,811$ & $397.5-1,348$ & \\
\hline Treated Median - U/liter & 330 & 224 & 0.072 \\
\hline$Q 1-Q 3$ & $297-401$ & $204-282$ & \\
\hline Red blood cells PNH clone $(I I+I I I$ type $)-\%$ & & & 0.223 \\
\hline Median & 68.7 & 55.5 & \\
\hline$Q 1-Q 3$ & $36.8-92.2$ & $24.3-65.4$ & \\
\hline Granulocyte PNH clone - \% & & & 0.462 \\
\hline Median & 94.85 & 95.55 & \\
\hline$Q 1-Q 3$ & $85.7-97.9$ & $71.0-97.3$ & \\
\hline Hemoglobin - g/liter & & & 0.353 \\
\hline Median & 93.5 & 100.5 & \\
\hline$Q 1-Q 3$ & $78.5-115$ & $90-126$ & \\
\hline Glomerular filtration rate, $\mathrm{mL} / \mathrm{min} / 1.73^{2}$ & & & 0.0253 \\
\hline Median & 86.8 & 117.1 & \\
\hline$Q 1-Q 3$ & $67.1-111.7$ & $94.5-122.1$ & \\
\hline Mean pulmonary pressure $-\mathrm{mmHg}$ & & & 0.808 \\
\hline Median & 22.5 & 22.5 & \\
\hline$Q 1-Q 3$ & $10-26.5$ & $10-25$ & \\
\hline EORTC QLQ-C30 - points & & & 0.375 \\
\hline Median & 49.4 & 54.4 & \\
\hline$Q 1-Q 3$ & $48.3-53.9$ & $48.9-57.2$ & \\
\hline FACIT-Fatigue - points & & & 0.067 \\
\hline Median & 36 & 40.5 & \\
\hline$Q 1-Q 3$ & $27-40.5$ & $32.5-47.5$ & \\
\hline$M A C-n g / m L$ & & & 0.109 \\
\hline Median & 237.05 & 161.87 & \\
\hline$Q 1-Q 3$ & $171.13-843.67$ & $133.81-217.34$ & \\
\hline
\end{tabular}

${ }^{\dagger}$ Race information provided by patients themselves

Notes: FACIT-Fatigue, Functional Assessment of Chronic Illness Therapy - fatigue scale; EORTC QLQC30, European Organization for Research and Treatment of Cancer Quality of Life Questionnaire; MAC, membrane attack complex
LDH AUC values were 62,957.6 $\pm 46,066.5 \mathrm{U} / \mathrm{L} *$ days $(95 \%$ CI $[38,410.4 ; 87,504.7])$ in Group $A$ and 49,702.6 $\pm 26,182.1$ U/L*days (95\% CI [34,585.5; 64,819.7]) in Group B $(p=0.351)$. Point estimation of the intergroup difference in LDH AUC amounted to 13,255.0 U/L*day (one-sided 95\% CI [- 10,492.9; 37,002.8]) (Fig. 4).

Estimation of the area under the LDH concentration-time curve (LDH AUC) between 1 and 26 weeks of treatment showed results similar to the primary endpoint, taking into account the high coefficient of variation, the LDH AUC value in the two groups (Table 3 ).

Comparable positive mean values of hemoglobin level changes during the period of maintenance therapy were noted in the both groups and amounted to $2.4 \pm 14.3 \mathrm{~g} / \mathrm{L}$ in Group A and 1.6 $\pm 12.2 \mathrm{~g} / \mathrm{L}$ in Group B.

Hemoglobin level stabilization (fluctuations not exceeding $5 \mathrm{~g} / \mathrm{L}$ ) during the maintenance therapy period was achieved in 6 of 16 patients $(37.5 \%)$ who received the 
Fig. 2 Mean pharmacokinetic curves for the recorded eculizumab serum steady-state concentration in the extensive examination

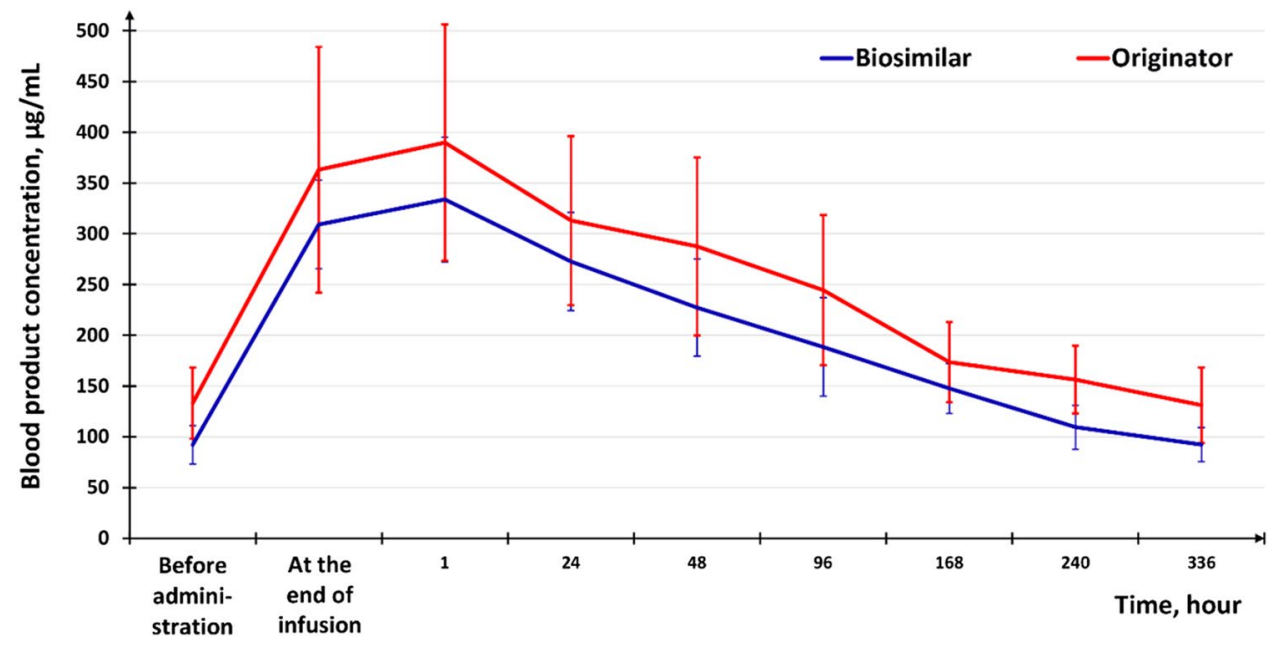

Biosimilar and in 2 of 14 patients (14.3\%) who received the Originator. In total, stabilization or increase in hemoglobin level was observed in 12 of 16 patients (75.0\%) who received the Biosimilar, and in 9 of 14 patients (64.3\%) who received the Originator (Fig. 5). Analysis of data in terms of the number and proportion of patients who needed pRBC transfusions, as well as in terms of the number of transfusions, revealed no statistically significant differences between the groups. In Group A, 2 of 16 patients (12.5\%) required blood transfusions, while there were 3 of 14 such patients (21.4\%) in Group B.

One thrombotic complication (thrombophlebitis of the cubital vein, at the medicinal product infusion site) was recorded in Group B. During the entire study period, 4 cases of breakthrough hemolysis were recorded in 3 of 16 patients (18.8\%) in Group A. The change in the mean
Table 2 Characteristics of pharmacokinetic parameters in both groups

\begin{tabular}{|c|c|c|c|c|}
\hline PK parameter & Parameter & Group A (Biosimilar) & Group B (Originator) & $P(\mathrm{mu})$ \\
\hline \multirow[t]{2}{*}{$\mathrm{C}_{\min }, \mu \mathrm{g} / \mathrm{mL}$} & M & 64.89 & 94.13 & \multirow[t]{2}{*}{0.065} \\
\hline & SD & 25.96 & 58.76 & \\
\hline \multirow[t]{2}{*}{$\mathrm{C}_{\max }, \mu \mathrm{g} / \mathrm{mL}$} & M & 351.35 & 407.45 & \multirow[t]{2}{*}{0.635} \\
\hline & SD & 114.44 & 263.63 & \\
\hline \multirow[t]{2}{*}{$\mathrm{C}_{\text {trough }}, \mu \mathrm{g} / \mathrm{mL}$} & M & 92.19 & 131.16 & \multirow[t]{2}{*}{0.075} \\
\hline & SD & 33.26 & 73.49 & \\
\hline \multirow[t]{2}{*}{$\mathrm{AUC}_{\mathrm{t}, \mathrm{ss}}, \mu \mathrm{g} * \mathrm{~h} / \mathrm{mL}$} & M & $53,579.37$ & $70,612.81$ & \multirow[t]{2}{*}{0.123} \\
\hline & SD & $20,853.74$ & $33,648.98$ & \\
\hline \multirow[t]{2}{*}{$\mathrm{T}_{\text {max }}, \mathrm{h}$} & M & 4.26 & 1.26 & \multirow[t]{2}{*}{0.415} \\
\hline & SD & 7.83 & 0.55 & \\
\hline \multirow[t]{2}{*}{$\mathrm{K}_{\mathrm{el}}, \mathrm{h}^{-1}$} & M & 0.0034 & 0.0028 & \multirow[t]{2}{*}{0.236} \\
\hline & SD & 0.0016 & 0.0011 & \\
\hline \multirow[t]{2}{*}{$\mathrm{T}_{1 / 2}, \mathrm{~h}$} & M & 375.08 & 277.00 & \multirow[t]{2}{*}{0.236} \\
\hline & SD & 598.62 & 83.75 & \\
\hline \multirow[t]{2}{*}{ MRT, h } & M & 536.63 & 408.15 & \multirow[t]{2}{*}{0.206} \\
\hline & SD & 858.25 & 135.57 & \\
\hline \multirow[t]{2}{*}{$\mathrm{CL}, \mathrm{mL} / \mathrm{h}$} & $\mathrm{M}$ & 11.97 & 8.50 & \multirow[t]{2}{*}{0.053} \\
\hline & SD & 6.14 & 3.56 & \\
\hline \multirow[t]{2}{*}{$\mathrm{V}_{\mathrm{ss}}, \mathrm{L}$} & M & 3.80 & 3.29 & \multirow[t]{2}{*}{0.385} \\
\hline & SD & 1.23 & 1.19 & \\
\hline
\end{tabular}

Notes: $C_{m i n}$, minimum product concentration; $C_{\max }$, maximum product concentration; $C_{\text {trough }}$, minimum product concentration at the end of the dosing interval after establishing a stationary distribution; $A U C_{t, s s}$, area under the concentration-time curve during the dosing interval after establishing a stationary distribution; $T_{\max }$, h, time to reach the maximum product concentration; $K_{e l}$, elimination constant; $T_{1 / 2}$, half-life; $M R T$, mean retention time; $C L$, clearance; $V_{s s}$, stationary specific volume of distribution 
Fig. 3 Mean pharmacodynamic curves for the recorded membrane attack complex values $(\mathrm{ng} / \mathrm{mL})$ in steady state in the extensive PK study

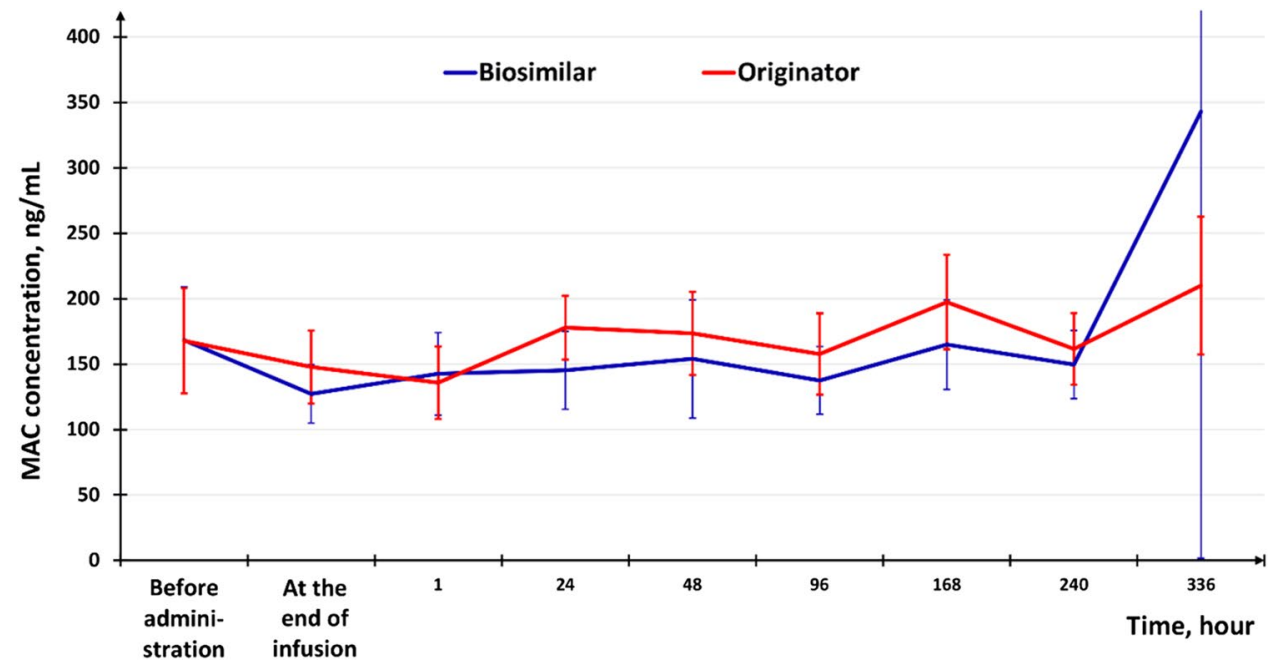

value of PNH clone of type II + III RBC and granulocytes in naive patients relative to the baseline value was similar in both groups.

The change in the total score of the questionnaires used was statistically insignificant in the compared groups. Thus, the mean value of the change in the total score of the EORTC QLQ-C30 at the end of the study relative to the baseline value at the screening amounted to $1.67 \pm 3.90$ points in Group $A$ and $-0.32 \pm 4.47$ points in Group B. Meanwhile, the mean values of the change in the total score of the FACIT-Fatigue at the end of the treatment period relative to the baseline value amounted to $8.1 \pm 8.7$ points in Groups $A$ and $2.3 \pm 6.6$ points in Group B.

\section{Safety}

A total of 13 ADRs were reported after the administration of the Biosimilar in 2 patients and Originator in 3 patients. They were associated with investigations, blood and lymphatic system disorders, infectious and parasitic diseases, kidney and urinary tract disorders, general disorders and administration site conditions, and metabolic and nutritional disorders, and had potential, probable, or definitive relation to the investigational medicinal products (Table 1 in supplement).

\section{Immunogenicity}

According to the immunogenicity analysis, no statistically significant differences between the groups in terms of antidrug antibodies (ADAs) detection frequency were identified at any of the Study Visits $(p>0.05)$. ADAs detected in two patients in Group A (Biosimilar) were formed as a result of
Fig. 4 Dynamics of lactate dehydrogenase activity during the study (95\% CI for the mean)

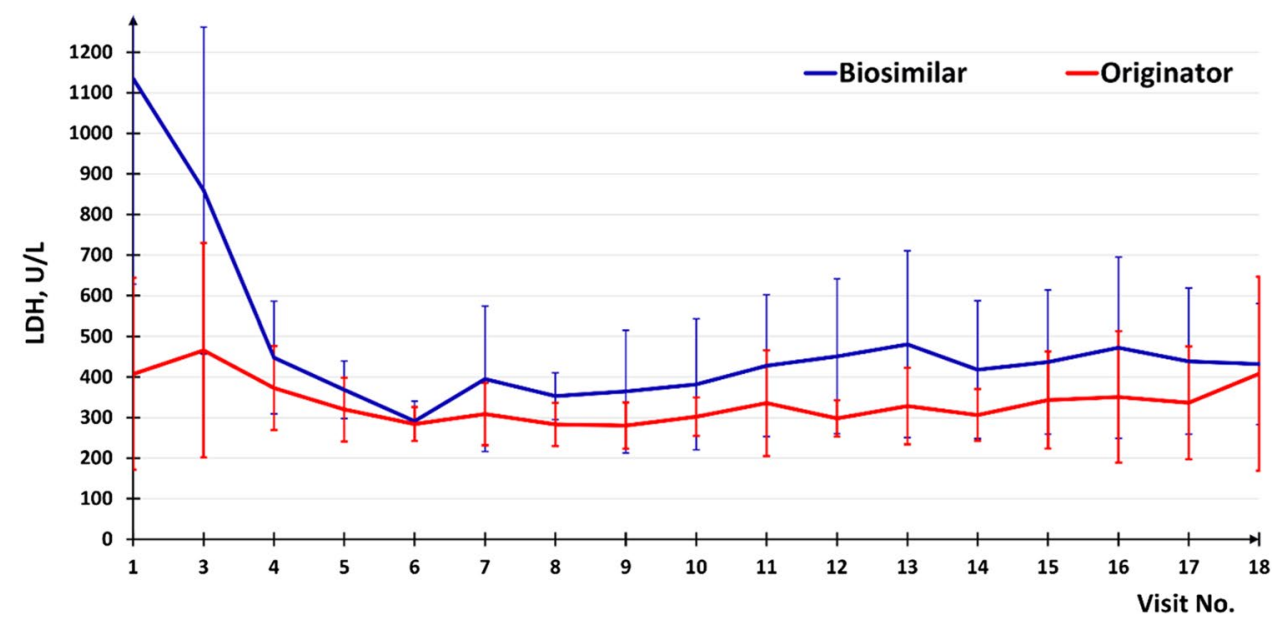


Table 3 The results of a comparative assessment of the secondary efficacy endpoints in the compared groups

\begin{tabular}{|c|c|c|c|}
\hline Secondary efficacy criterion & Biosimilar & Originator & $P$-value \\
\hline \multicolumn{4}{|l|}{ The area under the curve throughout the study, U/L*day } \\
\hline $\mathrm{M} \pm \mathrm{SD}$ & $75,670.1 \pm 49,432.2$ & $59,254.0 \pm 30,396.9$ & 0.291 \\
\hline Me; IQR & $66,991.25 ; 24,058.75$ & $52,915.75 ; 21,702.5$ & \\
\hline $95 \% \mathrm{CI}$ & $(49,329.5 ; 102,010.6)$ & $(41,703.3 ; 76,804.6)$ & \\
\hline \multicolumn{4}{|l|}{ Changes in hemoglobin level during the maintenance therapy period, $\mathrm{g} / \mathrm{L}$} \\
\hline $\mathrm{M} \pm \mathrm{SD}$ & $2.4 \pm 14.3$ & $2.8 \pm 13.1$ & 0.949 \\
\hline Me; IQR & $1 ; 15$ & $4 ; 20$ & \\
\hline 95\% CI & $(-5.2 ; 10.1)$ & $(-4.2 ; 9.7)$ & \\
\hline $\begin{array}{l}\text { Patients with stable hemoglobin level or its increase during the maintenance } \\
\text { therapy period }\end{array}$ & $12 / 16(75 \%)$ & $9 / 14(64.3 \%)$ & 0.585 \\
\hline Patients with various thrombotic complications & $0 / 16(0 \%)$ & $1 / 14(7 \%)$ & 1.000 \\
\hline Patients requiring transfusions of $R B C$-containing donor blood components & $2 / 16(12.5 \%)$ & $3 / 14(31.3 \%)$ & 0.642 \\
\hline Patients with breakthrough hemolysis & $3 / 16(18.8 \%)$ & $0 / 14(0 \%)$ & 0.228 \\
\hline \multicolumn{4}{|l|}{ Change in the PNH RBC clone size at Week 26 of treatment in naive patients, $\%$} \\
\hline $\mathrm{M} \pm \mathrm{SD}$ & $11.0 \pm 21.61$ & $11.60 \pm 9.19$ & 0.972 \\
\hline Me; IQR & $8.7 ; 33.3$ & $11.6 ; 13.0$ & \\
\hline $95 \% \mathrm{CI}$ & $(-11.68 ; 33.68)$ & $(-70.99 ; 94.19)$ & \\
\hline \multicolumn{4}{|l|}{ Change in the PNH granulocyte clone size at Week 26 of treatment, $\%$} \\
\hline $\mathrm{M} \pm \mathrm{SD}$ & $-0.55 \pm 4.89$ & $4.17 \pm 11.85$ & 0.228 \\
\hline Me; IQR & $0.3 ; 3.7$ & $2.0 ; 3.5$ & \\
\hline $95 \%$ CI & $(-3.16 ; 2.05)$ & $(-2.67 ; 11.01)$ & \\
\hline \multicolumn{4}{|l|}{ Changes in FACIT-Fatigue score } \\
\hline $\mathrm{M} \pm \mathrm{SD}$ & $8.1 \pm 8.7$ & $2.3 \pm 6.6$ & 0.053 \\
\hline Me; IQR & $7 ; 9.5$ & $4 ; 9.0$ & \\
\hline $95 \% \mathrm{CI}$ & $(3.4 ; 12.7)$ & $(-1.5 ; 6.1)$ & \\
\hline \multicolumn{4}{|l|}{ Changes in EORTC QLQ-C30 score } \\
\hline $\mathrm{M} \pm \mathrm{SD}$ & $1.67 \pm 3.90$ & $-0.32 \pm 4.47$ & 0.204 \\
\hline Me; IQR & $2.2 ; 5.3$ & $-0.3 ; 3.9$ & \\
\hline $95 \% \mathrm{CI}$ & $(-0.41 ; 3.74)$ & $(-2.90 ; 2.26)$ & \\
\hline
\end{tabular}

Notes: FACIT-Fatigue, Functional Assessment of Chronic Illness Therapy - fatigue scale; EORTC QLQ-C30, European Organization for Research and Treatment of Cancer Quality of Life Questionnaire; LDH AUC, area under the LDH concentration-time curve

previous therapy with the original medicinal product and did not have neutralizing activity. New cases of ADA formation were not revealed during the study.

\section{Discussion}

In this study, the noninferiority assessment of the efficacy of the first Biosimilar (Elizaria) relative to the Originator
Fig. 5 The dynamics of the hemoglobin level during the study period (error bar shows 95\% CI for the mean)

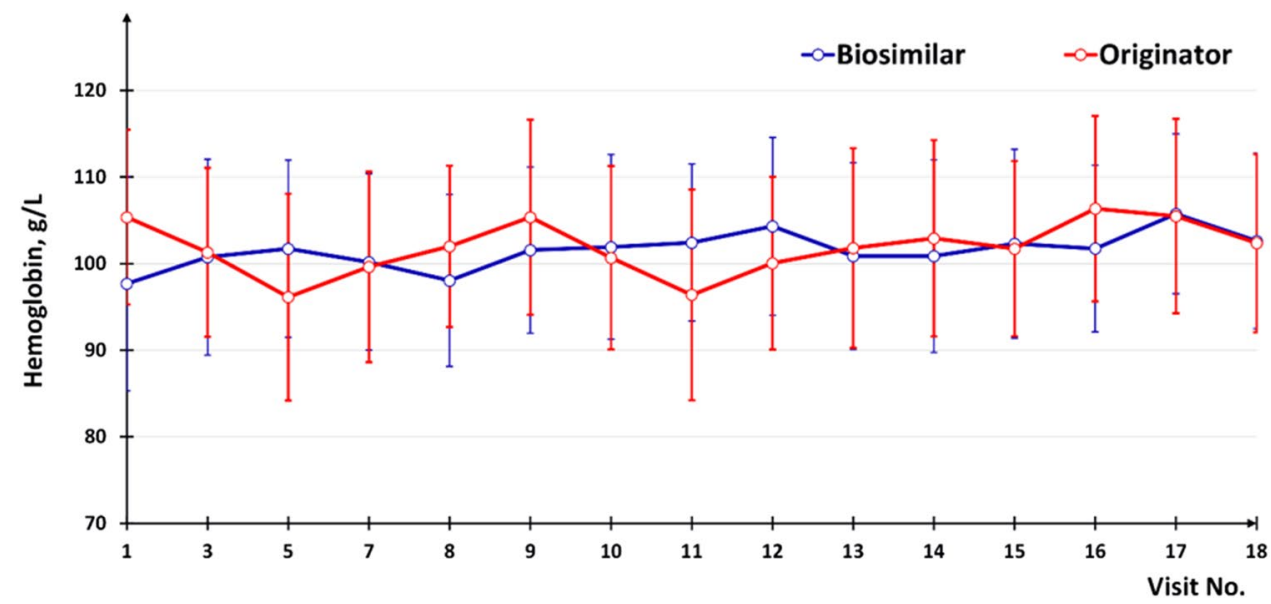


in treating PNH patients was made to confirm biosimilarity $[12,13]$. The result of the primary endpoint analysis (LDH AUC during maintenance therapy) showed that the Biosimilar is not inferior to the Originator in terms of efficacy. Thus, the point estimate of the LDH AUC intergroup difference was $13,255.0 \mathrm{U} / \mathrm{L} *$ days (one-sided 95\% CI [-10,492.9; $37,002.8]$ ), that is, the specified confidence interval did not cross the specified limit of noninferiority. In the PP population, which is the basis for efficacy analysis, the upper limit of the $95 \%$ CI of the LDH AUC difference was about $12.3 \%$ of the previously identified placebo-controlled effect.

The high frequency of hemoglobin level stabilization and dynamics of PNH RBC clone size act as additional confirmation of the efficacy of therapy due to a decrease in hemolytic activity. The number of episodes of breakthrough hemolysis and thrombotic complications, as well as the patient needs for $\mathrm{pRBC}$ transfusion, was insignificant and did not reveal significant differences between the Biosimilar and Originator. At the same time, the subjective state of the patients, investigated using the FACIT-Fatigue and EORTC QLQ-C30 questionnaires, confirmed the stability of laboratory and clinical data.

Extremely high variability of the baseline concentration of the medicinal product in both groups was noted during the analysis of the pharmacokinetic parameters: the coefficient of variation (CV) was $94.6 \%$ in Group A and $82.8 \%$ in Group B, respectively. The results obtained correspond to the conclusions of existing publications on the high variability of eculizumab, the concentration of which depends on the level of MAC and complement component C5, as well as on the age and sex of the patient population [19]. A decrease in medicinal product concentration variability was reported in both groups at subsequent time points, although the coefficient of variation at some points was significant and exceeded $50 \%$, which can be explained by the achievement of stable complement inhibition. The mean concentration of eculizumab 5 min before the administration of the Biosimilar or Originator at all the visits before and in the steady state exceeded $35 \mu \mathrm{g} / \mathrm{mL}$ which is the minimum concentration sufficient enough for complete inhibition of intravascular hemolysis in patients with PNH [20,21]. Also, high variability of individual pharmacokinetic parameters may be due to their significant dependence on the patient's body weight [22].

According to pharmacodynamic studies, the concentration of MAC decreases after the end of the product infusion, then gradually increases and reaches its maximum at the end of the dosing interval, which confirms the pathophysiological activity of the medicinal product [23].

The overall safety profile of the Biosimilar was consistent with that of the Originator, and no cases of meningococcal or other severe infection or unexpected ADRs were reported. The proportion of patients with registered ADRs and the dynamics of laboratory and instrumental examination data in both treatment groups were comparable. New cases of ADA formation were not registered during the study, which indicates the absence of significant differences in safety parameters and is consistent with similar studies of biosimilars [24].

The main limitation of the clinical study was the low number of PNH patients, as well as the orphan status of eculizumab, which complicates the formation of a comparison group. These limitations influenced the choice of study design, efficacy endpoints, and sample size.

The use of a noninferiority design was justified by the fact that no substantial and clinically significant excess of efficacy was expected for the Biosimilar compared to the Originator when using the same regimen since the clinical efficacy of eculizumab is primarily determined by the minimum concentration sufficient to inhibit the activity of the terminal complement complex. According to the results of clinical studies of the Originator, this value in $\mathrm{PNH}$ patients is about $35 \mu \mathrm{g} / \mathrm{mL}[16,24]$. The noninferiority design is often used in comparative studies of biosimilars as well [25].

Thus, long-term use of eculizumab Biosimilar leads to successful inhibition of the complement hemolytic activity in PNH patients. The assessment of the efficacy and safety of the Biosimilar showed no less efficacy and comparability in terms of safety with the Originator, which is necessary to confirm its biosimilarity to the original medicinal product.

Supplementary Information The online version contains supplementary material available at https://doi.org/10.1007/s00277-021-04624-7.

Acknowledgements The authors would like to thank all the investigators and patients who participated in this study.

Author contribution Authors D.A.K.", E.V.G.,, O.A.M. planned this study, developed its theoretical basis, reviewed the study protocol, and interpreted the data for manuscript together with A.D.K.", V.V.P., E.A.L., and I.L.D.; A.D.K*, E.A.L., I.L.D., A.V.K., V.V.P., V.S.Sh., T.S.K., T.S.K., T.A.M., and T.I.K. performed the study on their investigational sites, carried out medical supervision and treatment of PNH patients enrolled. A.D.K. , V.V.P., E.A.L., and I.L.D. have critically reviewed this manuscript; E.V.G." supervised the study; O.A.M. and E.V.Z. wrote the manuscript.

\section{Declarations}

Conflict of interest Kulagin A.: Alexion Pharmaceuticals, Inc: Consultancy, Research Funding (to Pavlov University); JSC GENERIUM: Consultancy, Honoraria, Research Funding (to Pavlov University). Ptushkin V.: Alexion Pharmaceuticals, Inc.: Consultancy, Research Funding; JSC GENERIUM: Research Funding; Janssen: Consultancy; AbbVie: Consultancy; Roche: Consultancy. Lukina E.: JSC GENERIUM: Research Funding; Sanofi Genzyme: Honoraria, Membership on an entity's Board of Directors or advisory committees, Other: Travel Reimbursement, Research Funding; Shire: Honoraria, Membership on an entity's Board of Directors or advisory committees, Other: Travel Reimbursement. Gapchenko E.: JSC GENERIUM: Employment. Markova O.: JSC GENERIUM: Employment. Zuev E.: JSC GENERIUM: Employment. Kudlay D.: JSC GENERIUM: Employment. 
Open Access This article is licensed under a Creative Commons Attribution 4.0 International License, which permits use, sharing, adaptation, distribution and reproduction in any medium or format, as long as you give appropriate credit to the original author(s) and the source, provide a link to the Creative Commons licence, and indicate if changes were made. The images or other third party material in this article are included in the article's Creative Commons licence, unless indicated otherwise in a credit line to the material. If material is not included in the article's Creative Commons licence and your intended use is not permitted by statutory regulation or exceeds the permitted use, you will need to obtain permission directly from the copyright holder. To view a copy of this licence, visit http://creativecommons.org/licenses/by/4.0/.

\section{References}

1. Rosse WF, Ware RE (1995) The molecular basis of paroxysmal nocturnal hemoglobinuria. Blood 86(9):3277-3286

2. Hillmen P, Hall C, Marsh J et al (2004) Effect of eculizumab on hemolysis and transfusion requirements in patients with paroxysmal nocturnal hemoglobinuria. N Engl J Med 350(6):552-559

3. Hillmen P, Muus P, Duhrsen U et al (2007) Effect of the complement inhibitor eculizumab on thrombembolizm in patients with paroxysmal nocturnal hemoglobinuria. Blood 110:4123-4128

4. Parker C, Omine M, Richards S et al (2005) Diagnosis and management of paroxysmal nocturnal hemoglobinuria. Blood 106(12):3699-3709

5. Hillmen P, Young N, Schubert J et al (2006) The complement inhibitor eculizumab in paroxysmal nocturnal hemoglobinuria. N Engl J Med 355(12):1233-1243

6. Johnson R, Hillmen P (2002) Paroxysmal nocturnal haemoglobinuria: nature's gene therapy? J Clin Pathol: Mol Pathol 55(3): $145-152$

7. Noris M, Caprioli J, Bresin E et al (2010) Relative role of genetic complement abnormalities in sporadic and familial aHUS and their impact on clinical phenotype. Clin J Am Soc Nephrol 5:1844-1859

8. Reiss UM, Schwartz J, Sakamoto KM et al (2014) Efficacy and safety of eculizumab in children and adolescents with paroxysmal nocturnal hemoglobinuria. Pediatr Blood Cancer 61(9):15441550. https://doi.org/10.1002/pbc.25068

9. Fakhouri F, Fremeaux-Bacchi V (2007) Does hemolytic uremic syndrome differ from thrombotic thrombocytopenic purpura. Nat Clin Pract Nephrol 3(12):679-687

10. Hillmen P, Muus P, Roth A et al (2013) Long-term safety and efficacy of sustained eculizumab treatment in patients with paroxysmal nocturnal haemoglobinuria. Br J Haematol 162(1):62-73. https://doi.org/10.1111/bjh.12347

11 Kulagin A, Klimova O, Rudakova T et al (2018) Benefits and limitations of long-term eculizumab treatment for paroxysmal nocturnal hemoglobinuria ( $\mathrm{PNH})$ : real-world data from large cohort study in Russia. Blood 132(s1):2589. https://doi.org/10. 1182/blood-2018-99-120139

12. Rules for conducting research of biological medicines of the Eurasian Economic Union. Astana. 2016. 714 p. [Electronic source] https://docs.eaeunion.org/docs/ru-ru/01411954/cncd_21112016_ 89. Accessed 11 Sept 2020

13. Guideline on similar biological medicinal products containing biotechnology-derived proteins as active substance: non-clinical and clinical issues. EMEA/CHMP/BMWP/42832/2005 Rev1. 2015. 13c. [Electronic source] https://www.ema.europa.eu/en/ similar-biological-medicinal-products-containing-biotechnologyderived-proteins-active-substance-non. Accessed 11 Sept 2020

14. Ivanov R, Sekaryova G, Kravtsova O et al (2014) Rules for the performance of studies of biosimilar medicinal products (Biosimilars). Farmakokinetika i Farmakodinamika [Pharmacokinetics and Pharmacodynamics] 1:21-36

15. Ptushkin VV, Kulagin AD, Lukina EA et al (2020) Results of phase Ib open multicenter clinical trial of the safety, pharmacokinetics and pharmacodynamics of first biosimilar of eculizumab in untreated patients with paroxysmal nocturnal hemoglobinuria during induction of therapy. Ter Arkh 92(7):77-84. https://doi. org/10.26442/00403660.2020.07.000818

16 Kulagin A, Ptushkin V, Lukina E et al (2019) Phase III clinical trial of Elizaria ${ }^{\circledR}$ and Soliris ${ }^{\circledR}$ in adult patients with paroxysmal nocturnal hemoglobinuria: results of comparative analysis of efficacy, safety, and pharmacological data. Blood. 134(s1):3748. https://doi.org/10.1182/blood-2019-125693

17. Sipol AA, Babenko EV, Borisov VI et al (2015) An inter-laboratory comparison of PNH clone detection by high-sensitivity flow cytometry in a Russian cohort. Hematology 20(1):31-38. https:// doi.org/10.1179/1607845414Y.0000000162

18. Hillmen P, Young NS, Schubert J, Brodsky RA, Socié G, Muus P, Röth A, Szer J, Elebute MO, Nakamura R, Browne P, Risitano AM, Hill A, Schrezenmeier H, Fu CL, Maciejewski J, Rollins SA, Mojcik CF, Rother RP, Luzzatto L (2006) The complement inhibitor eculizumab in paroxysmal nocturnal hemoglobinuria. $\mathrm{N}$ Engl J Med 355(12):1233-1243. https://doi.org/10.1056/NEJMo a061648 (PMID: 16990386)

19. Wijnsma KL, Heine RT, Moes DJAR et al (2019) Pharmacology, pharmacokinetics and pharmacodynamics of eculizumab, and possibilities for an individualized approach to eculizumab. Clin Pharmacokinet 58:859-874. https://doi.org/10.1007/ s40262-019-00742-8

20. US Food and Drug Administration (FDA) (2007) Clinical pharmacology and biopharmaceutics review. Silver Spring: US FDA

21. European Medicines Agency (EMA). Soliris: EPAR-product information. EMEA/H/C/000791 - II/0113. Last updated: 01/07/2020. [Electronic source] https://www.ema.europa.eu/en/ documents/product-information/soliris-epar-product-information en.pdf. Accessed 26 Oct 2020

22. Jodele S, Fukuda T, Mizuno K et al (2016) Variable eculizumab clearance requires pharmacodynamic monitoring to optimize therapy for thrombotic microangiopathy after hematopoietic stem cell transplantation. Biol Blood Marrow Transplant 22(2):307-315

23. Brodsky R (2014) Paroxysmal nocturnal hemoglobinuria. Blood 124(18):2804-2811

24. Stoppa G, D'Amore C, Conforti A et al (2018) Comparative safety of originator and biosimilar epoetin alfa drugs: an observational prospective multicenter study. BioDrugs 32:367-375. https://doi. org/10.1007/s40259-018-0293-2

25. Kim WS, Buske C, Ogura M et al (2017) Efficacy, pharmacokinetics, and safety of the biosimilar CT-P10 compared with rituximab in patients with previously untreated advanced-stage follicular lymphoma: a randomised, double-blind, parallel-group, non-inferiority phase 3 trial. Lancet Haematol 4(8):e362-e373. https://doi.org/10.1016/S2352-3026(17)30120-5

Publisher's Note Springer Nature remains neutral with regard to jurisdictional claims in published maps and institutional affiliations. 